\title{
Television food advertising to children: the extent and nature of exposure
}

\author{
Bridget Kelly ${ }^{1}$, Ben Smith ${ }^{1}$, Lesley King ${ }^{2, *}$, Victoria Flood ${ }^{3}$ and Adrian Bauman ${ }^{1}$ \\ ${ }^{1}$ Australian Centre for Health Promotion, School of Public Health, University of Sydney, Sydney, New South Wales, \\ Australia: ${ }^{2}$ NSW Centre for Overweight and Obesity, School of Public Health, Level 2, K25 Medical Foundation \\ Building, University of Sydney, Sydney, New South Wales 2006, Australia: ${ }^{3}$ NSW Centre for Public Health Nutrition, \\ Department of Molecular and Microbial Biosciences, University of Sydney, Sydney, New South Wales, Australia
}

Submitted 30 August 2006: Accepted 19 December 2006: First published online 5 March 2007

\begin{abstract}
Objective: To describe the pattern and prevalence of food and drink advertisements to children on commercial television in Sydney, Australia, and compare these with advertising regulations set out in the Children's Television Standards and results from a similar study in 2002 .

Design: Data were collected by recording television from 06.00 hours until 23.00 hours on all three commercial channels from Sunday 14 May 2006 to Saturday 20 May 2006 $(357 \mathrm{~h})$. The study analysed advertisements in two children's viewing periods, one as defined in the 2002 study and the other according to current standards. Food advertisements were coded using 18 food categories and were analysed by time period and popular children's programmes.

Results: Food advertisements occurred in similar proportions during children's viewing hours and adult's viewing hours (25.5 vs. 26.9\% of all advertisements, respectively), although there was a higher rate of high-fat/high-sugar food advertisements during children's viewing hours (49 vs. $39 \%$ of all food advertisements, $P<0.001)$. There were even more advertisements for highfat/high-sugar foods during popular children's programmes, contributing to $65.9 \%$ of all food advertisements. Estimates of exposure indicate that children aged 5-12 years were exposed to 96 food advertisements, including 63 high-fat/high-sugar advertisements per week. Since 2002, there has been a reduction in overall food and high-fat/high-sugar food advertisements.

Conclusion: Despite reductions in overall levels of food advertising, children continue to experience high levels of exposure to food advertisements, which remain skewed towards unhealthy foods. Further food advertising regulation should be required to curtail the current levels of advertising of high-fat/high-sugar foods to children, to make them commensurate with recommended levels of consumption.
\end{abstract}

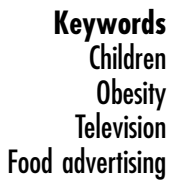

In the past two decades, there has been a significant increase in the proportion of overweight and obese children in Australia, a trend that has also been reported in a number of other countries ${ }^{1,2}$. The most recent population data for Australia were collected among school students in New South Wales, where it was found that $25 \%$ of students in school years 2-10 were overweight or obese . $^{3}$.

Television viewing has been identified as a factor contributing to the problem of childhood overweight and obesity ${ }^{4}$. Television viewing is a significant component of total sedentary behaviour ${ }^{3}$ and has been found to be positively correlated with total caloric intake ${ }^{5}$ and the consumption of snack foods ${ }^{6}$.

Exposure to advertising of unhealthy food products is one of the means by which television viewing contributes to overweight and obesity. Television food advertisements have been linked to children's food preferences, at both brand and category levels ${ }^{7,8}$, and to both purchasing and consumption habits 9 . The recent systematic review by the United States Institute of Medicine ${ }^{4}$ found strong evidence that food and beverage preferences and purchase requests from children aged 2-11 years are influenced by television food advertising. Some researchers report a link not only between viewing of food advertisements, consumption of snack foods and caloric intake, but also between advertisement exposure and increased body weight ${ }^{7}$.

There appears to be a disparity between the range of food products advertised on television and the diet that is recommended for health. Hastings et al. ${ }^{7}$ reported that the five most frequently advertised product categories were breakfast cereals, confectionery, savoury snacks, fast-food 
restaurants and soft drinks. Consequently, children who view a greater number of television advertisements have been found to consume a larger quantity of non-core foods, particularly sweet and high-fat savoury foods ${ }^{6}$. The Australian Guide to Healthy Eating recommends that not more than two servings of non-core foods (i.e. those high in sugar and/or fat) should be consumed each day ${ }^{10}$. This is the equivalent of approximately $14 \%$ of daily energy intake for children aged 5-12 years. Population data for Australia show that, in practice, these foods contribute more than $40 \%$ of energy intake for children and adolescents $^{11}$.

As a result of such trends, the nature and extent of television advertising has come under increasing scrutiny in a number of countries. In New Zealand, the rates of food advertisements have been found to be increasing, from eight per hour in 1997 to 12 per hour in $2006^{12}$. An international study conducted in 1996 on television food advertising patterns indicated that Australia, the USA and the UK had the highest proportion of overall food advertisements, with 83, 98 and 79\% of these food adverts, respectively, for sweet/fatty foods 9 .

The question of whether food advertising to children should be more strongly regulated has been raised in several countries ${ }^{13}$. Children less than 8 years of age, in particular, are thought to lack the cognitive skills required to recognise an advertiser's persuasive intent and purpose $^{4,14}$, and are therefore more at risk of commercial exploitation. The need to protect children from commercial exploitation has been recognised by a wide range of public health groups; and the International Code of Advertising Practice has stated that advertisements should not manipulate the inexperience of children ${ }^{15}$.

The Children's Television Standards (CTS) were introduced in Australia in 1990, and have been under the jurisdiction of the Australian Communications and Media Authority (ACMA) since $2005^{16}$. The current system of coregulation in Australia is comprised of three regulatory frameworks, including both industry and government regulations, of which the CTS is the overriding standard. The CTS relates to advertising broadcast during children's programming, where children are defined as people younger than 14 years old. These regulations refer to maximum advertising time and the repetition of advertisements, and define children's viewing periods. These children's viewing periods have been adopted by all three regulatory codes. Among other recommendations, this code states that advertisements directed to children should not promote unhealthy eating or drinking habits.

The aim of the current study was to undertake a detailed examination of the extent and type of food advertisements in Sydney, the largest population centre in Australia with a population of $4254900^{17}$. Patterns of advertising were examined within the weekly time period agreed to be children's viewing hours under the prevailing regulations, and within a more selected band of viewing time for which comparable data were available from 2002. The focus of the research was high-fat/high-sugar foods and the potential exposure of children to advertising for these foods under the current regulatory system.

\section{Methods}

\section{Sample week television recording}

Data were collected by recording all television, from 06.00 until 23.00 hours on Sydney television stations from Sunday 14 May 2006 to Saturday 20 May 2006, using an established monitoring system at the University of Sydney. Of five free-to-air channels, data were collected from the three commercial channels. All data were screened by three research assistants, with all advertisements identified, logged and classified as either for food or non-food, and the duration of the advertisement recorded. This sample week was selected as it matched the period of data collection in the similar 2002 study $^{18}$, which assessed the same television channels during a corresponding sample week in 2002.

\section{Children's viewing bours}

The children's television viewing periods were categorised in two ways:

1. Children's television viewing band one (Viewing band 1 ), as set down in the ACMA CTS (Monday-Friday 07.00-08.00 and 16.00-20.30, Saturday-Sunday 07.00-20.30).

2. Children's television viewing band two (Viewing band 2), which was the same as that used in the 2002 study (Monday-Friday 06.30-07.30, 09.00-09.30 and 15.00-16.30, Saturday-Sunday 07.00-11.30).

Viewing band 1 included $54.5 \mathrm{~h}$ per week per channel, and Viewing band 2 comprised $24 \mathrm{~h}$ of television per week per channel. The more extensive children's viewing hours, Viewing band 1, was used as the basis for describing the current extent of television advertising to children. The data for Viewing band 2 comprised a subset and were used to compare advertising patterns between 2006 and 2002.

Food advertisements were coded using the food categories from the comparable 2002 study, which consisted of 18 food group categories, divided into the three major groups: core foods, high-fat/high-sugar foods and miscellaneous foods (refer to Table 1 for the list of food types categorised into each group). All food coding was conducted by a research dietitian (B.K.).

\section{Television viewing patterns}

In order to explore patterns of advertising during highratings programmes, data on the 20 highest rating programmes for 5-12-year-olds, 13-17-year-olds and people 18 years and over were obtained from OzTAM Pty $\operatorname{Ltd}^{19}$. 
Table 1 The frequency of food categories advertised during children's viewing hours and nonchildren's viewing hours

\begin{tabular}{|c|c|c|}
\hline \multirow[b]{2}{*}{ Food category } & \multicolumn{2}{|c|}{$\%$ of food advertisements } \\
\hline & Viewing band $1 \dagger$ & Adults' band \\
\hline Core foods & 34.2 & 37.2 \\
\hline Dairy & $9.6^{*}$ & 7.4 \\
\hline Fruit and vegetables & 3.0 & 2.8 \\
\hline Meat, fish, poultry & 4.4 & 5.0 \\
\hline Breads $\ddagger$ cereals, rice, pasta & 8.7 & 10.6 \\
\hline Baby foods & $1.1^{\star \star \star}$ & 3.3 \\
\hline Core food combined & 7.4 & 8.1 \\
\hline High-fat/high-sugar foods & $48.6^{\star \star \star}$ & 39.0 \\
\hline Confectionery & 12.2 & 13.4 \\
\hline Fast-food restaurants & $14.5^{\star \star \star}$ & 8.3 \\
\hline Cakes, biscuits, muesli bars & 6.7 & 5.1 \\
\hline High-fat/high-sugar spreads & 0.0 & 0.0 \\
\hline Breakfast cereals ( $>20 \%$ sugar) & 6.1 & 5.0 \\
\hline Sugared drinks & $3.6^{\star \star \star}$ & 1.1 \\
\hline Frozen/fried potato products & 0.0 & 0.0 \\
\hline Juice & $1.0^{\star \star \star}$ & 2.9 \\
\hline Savoury crisps and pastries & 3.1 & 2.1 \\
\hline Desserts & 1.4 & 1.1 \\
\hline Miscellaneous & $17.3^{\star \star \star}$ & 23.8 \\
\hline Recipe helpers & 6.6 & 7.2 \\
\hline Miscellaneous§ & $10.7^{* \star *}$ & 16.6 \\
\hline Alcohol & 0.9 & 0.7 \\
\hline
\end{tabular}

† Viewing band 1 includes Monday-Friday 07.00-08.00, 16.00-20.30; and Saturday-Sunday 07.00-20.30. $\ddagger$ Includes breakfast cereals with $<20 \%$ sugar.

$\S$ Includes tea, coffee, alcohol, supermarkets, local restaurants/cafes, supplements, vegemite and throat lozenges.

${ }^{*} P<0.05 ; P<0.001$.

\section{Statistical analyses}

Data from recorded television advertising were initially entered into an Excel 2003 database (Microsoft Corporation). The statistical analyses were conducted using SPSS, version 12 (SPSS for Windows). The proportions of foods in various categories were analysed, applying the $\chi^{2}$ test for significance. $P$-values of $<0.05$ were considered statistically significant.

\section{Results}

\section{Food advertising during children's viewing bours}

During the study period, there were a total of 9991 advertisements on three Sydney commercial television stations, with 2621 food advertisements. During Viewing band 1, food advertisements comprised 28.3\% of total advertisements on weekdays and $22.4 \%$ on weekends, with an overall proportion of $25.5 \%$ and a rate of 7.2 food advertisements per hour. This compared with $27 \%$ of food advertisements on weekdays and $25.6 \%$ on weekends, and an overall proportion of $26.9 \%$ and a rate of 7.4 food advertisements per hour during adults' viewing hours. Within Viewing band 1, there were significantly more food advertisements during afternoon/evening time periods than in the mornings (27.2 vs. $20.4 \%, \chi^{2}=21.6$, $P<0.001)$ and more on weekdays than weekend days (28.3 vs. $22.4 \%, \chi^{2}=21.2, P<0.001$ ).

\section{Types of food advertised}

While there was little variation in the number of food advertisements between children's and adults' viewing times, the types of foods advertised varied significantly (Table 1). During Viewing band 1, core foods comprised $34 \%$ (rate of 2.5 advertisements per hour) and high-fat/ high-sugar foods comprised 49\% (3.5 advertisements per hour) of total food advertisements. This contrasts with 39\% of advertisements being for high-fat/high-sugar foods during adults' viewing hours $\left(\chi^{2}=23.9, P<0.001\right)$, a rate of 2.9 advertisements per hour.

The most frequently advertised food groups for Viewing band 1 were fast-food restaurants (14.5\%), confectionery (12.2\%), dairy products $(9.6 \%)$ and bread, cereals, rice and pasta (8.7\%). A miscellaneous group, including tea, coffee, alcohol, supermarkets, local restaurants/cafes, supplements, yeast extracts and throat lozenges, comprised $10.7 \%$ of food advertisements, with alcohol contributing to $0.9 \%$ of total food advertisements during this time.

The highest concentration of high-fat/high-sugar advertisements was seen in the Viewing band 1 morning period, when these comprised $54.3 \%$ of food advertisements. The main contributing food at this time was high-sugar breakfast cereals (36\% of high-fat/high-sugar advertisements). Weekend days had a higher frequency of highfat/high-sugar advertisements than weekdays for both children's and adults' viewing times. The proportion of 
high-fat/high-sugar advertisements during the Viewing band 1 weekend times was marginally higher than that during adults' viewing hours on weekends (49.9 vs. $44.6 \%$, $\left.\chi^{2}=1.08, P=0.30\right)$.

\section{Food advertising during bigh-rating programmes}

The 20 most popular programmes on Sydney commercial television during the study week accounted for $13.5 \mathrm{~h}$ of viewing time per week for 5-12-year-olds and $16 \mathrm{~h}$ per week for $13-17$-year-olds. The majority of these programmes fell in the afternoon/evening time periods, when food advertising was most concentrated. There was a high rate of food advertisements during these periods, at 14 per hour (41.0\%) in the programmes popular with younger children (aged 5-12 years) and 12 per hour (36.5\%) during programmes popular with older children (13-17 years). The difference between core and high-fat/high-sugar foods advertised was also greater during high-rating programmes, with highfat/high-sugar foods the subject of $65.9 \%$ of food advertisements (rate of 9 advertisements per hour) during programmes popular with younger children and $66.8 \%$ of food advertisements (rate of 8 advertisements per hour) during programmes popular with older children. The proportion of these advertisements declined during the lower-ratings periods for 5-12year-olds $\left(41.6 \%, \chi^{2}=41.6, P \leq 0.001\right)$ and $13-17$-yearolds (41.5\%, $\chi^{2}=45.5, P<0.001$ ) (see Table 2, Fig. 1).

\section{Comparison with 2002 study data}

The data on 2006 food advertising during Viewing band 2 were compared with patterns described for 2002. Overall, the rates of food advertising on commercial Sydney television during Viewing band 2 were reduced significantly from 31 to $25.9 \%\left(\chi^{2}=17.9, P<0.001\right)$. The overall proportion of high-fat/high-sugar food advertisements also decreased, from $47.7 \%$ of all Viewing band 2 food advertisements in 2006 compared with 54\% in 2002 $\left(\chi^{2}=6.2, P=0.01\right.$, see Fig. 2 ). For this viewing period, there was an average of 3.0 advertisements per hour for high-fat/high-sugar foods in 2006, compared with 4.4 in 2002.

In both 2002 and 2006, the weekday afternoon children's viewing time slot had the largest proportion of food advertisements. Despite the overall differences between 2002 and 2006, the proportion of food advertisements in the Viewing band 2 weekday afternoon time slot in 2006 was $38 \%$, which is similar to the $37 \%$ found in 2002. In 2006, during the weekday afternoon viewing time, there was an average of $3.7 \mathrm{~min}$ of food advertisements per hour per channel (compared with $5 \mathrm{~min}$ in 2002).

In terms of specific foods, the proportion of confectionery advertisements within all food advertisements decreased between 2002 and 2006 (16.6 vs. 13.4\%, $\left.\chi^{2}=2.9, \quad P=0.09\right)$ whereas the proportion of food advertisements that were promoting fast-food restaurants declined over this period (13 vs. 9.2\%, $\chi^{2}=5.0, P=0.02$ ).

\section{Discussion}

Overall, about a quarter of advertisements on Sydney commercial television were for food. While the proportion of all advertisements that were for food was similar for children's and adults' viewing hours, the foods advertised during children's viewing hours were more likely to be high-fat/high-sugar foods.

These findings indicate that under the current coregulatory system in Australia, including the government's CTS, children have a high level of exposure to advertising for unhealthy food products. High-fat and high-sugar foods were the subject of about 50\% of overall food advertisements, and this was even higher during programmes popular with children, at $65.9 \%$ of all food advertisements. Adopting a conservative assumption that half of the average daily television viewing time of children and young people in Sydney, estimated to be $2.1 \mathrm{~h}$, is of commercial stations, then they would be exposed to 50 food advertisements, including 24 highfat/high-sugar foods per week (assuming 7.2 food advertisements per hour). If we were to assume that children were viewing their quantum of television during popular programmes, the estimate of food advertising exposure would be markedly higher, i.e. children aged 5-12 years would be exposed to 96 food advertisements, including 63 high-fat/high-sugar advertisements per week.

Although direct comparisons with other studies are difficult due to differences in the classification of 'noncore' foods, the results from this study were consistent with previous data, which have shown a large disparity

Table 2 The rate and proportion of high-fat/high-sugar advertisements during the most popular programmes, stratified by age group

\begin{tabular}{lccccc}
\hline & \multicolumn{2}{c}{ During the top 20 programmes } & & \multicolumn{2}{c}{ Other viewing times } \\
\cline { 2 - 3 } & $\begin{array}{c}\text { Rate high-fat/high-sugar } \\
\text { ads per hour }\end{array}$ & $\begin{array}{c}\text { \% high-fat/high-sugar } \\
\text { ads per food ads }\end{array}$ & $\begin{array}{c}\text { Rate high-fat/high-sugar } \\
\text { ads per hour }\end{array}$ & $\begin{array}{c}\text { \% high-fat/high-sugar } \\
\text { ads per food ads }\end{array}$ \\
\hline $5-12$ years & 9.0 & $65.9^{\star \star \star}$ & $66.8^{\star \star \star}$ & 3.0 & 41.6 \\
$13-17$ years & 7.8 & 41.9 & 3.0 & 4.5 \\
$18+$ years & 3.1 & & 3.2 & 43.4 \\
\hline
\end{tabular}

${ }^{\star \star *} P<0.001$. 


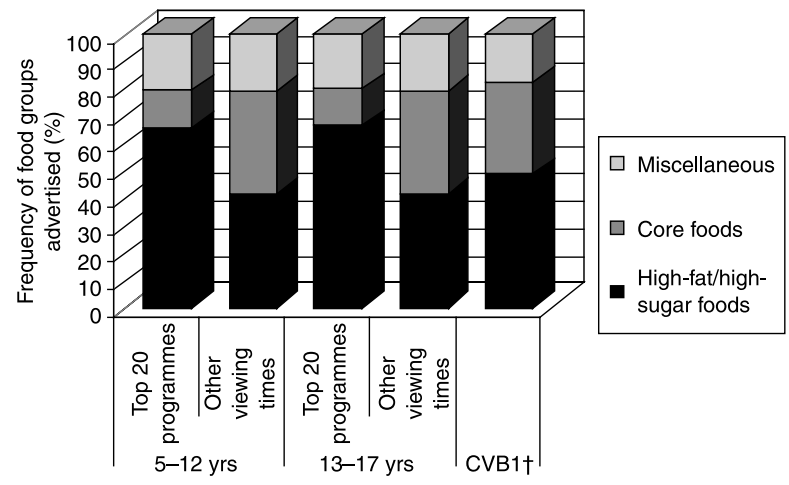

Fig. 1 The proportion of food advertisements for different food groups advertised during popular programmes. †CVB1 includes Monday-Friday $07.00-08.00,16.00-20.30$; and SaturdaySunday $07.00-20.30$

between the numbers of 'core' and 'non-core' foods advertised. A study describing the content of UK television advertising showed that a total of $35 \%$ of advertisements were for food, with the most commonly advertised food groups being high-sugar breakfast cereals (26.3\% of food advertisements) and confectionery $(23.7 \%)^{20}$. Similarly, data from the USA have shown that advertising during children's Saturday morning programmes consists of $57 \%$ food advertisements, with $44 \%$ classified as fats, oils and sweet foods ${ }^{21}$. A study of food advertising in New Zealand, using identical food coding to that of the current study, showed food advertising comprising $42 \%$ of all advertisements, of which $80 \%$ were for high-fat/high-sugar foods ${ }^{12}$. A recent study of television food advertisements across four population centres in Australia, using a less conservative system that categorised advertised foods as core or non-core, also showed the predominance of advertisements for non-core foods, at $81 \%$ as compared with $19 \%$ of advertisements for core foods ${ }^{22}$.

The analysis of advertising during the high-ratings programmes of 5-12-year-olds and 13-17-year-olds allowed both programme ratings and advertising frequency to be considered. Both of these aspects have not been addressed concurrently in previous Australian

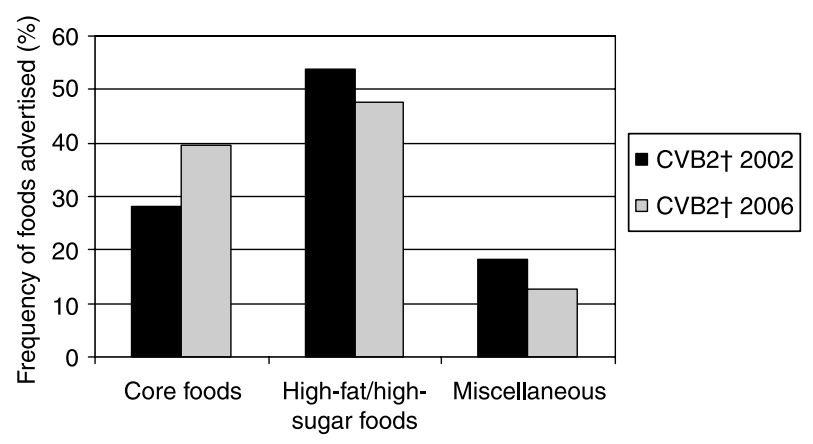

Fig. 2 The proportion of core foods, high-fat/high-sugar foods and miscellaneous foods advertised during children's viewing hours, comparison of 2002 and 2006 data. TCVB2 includes Monday-Friday 06.30-07.30, 09.00-09.30 and 15.00-16.30, SaturdaySunday $07.00-11.30$ studies. These analyses clearly showed that the programmes most popular with children and young people have a significantly higher proportion of total food and high-fat/high-sugar food advertisements when compared with other viewing times. These finding indicate, first, that past studies which have only measured the volume of food advertising are likely to have underestimated population-wide exposure of young people to advertisements of unhealthy products. Second, the inflated proportion of high-fat/high-sugar food advertisements during popular programmes confirms that children are the target of these commercial promotions. This is reflected in commercial marketer's ability to identify and dominate advertising during expensive high-ratings periods.

In view of these findings about the nature and extent of food advertising to children, it was surprising to observe that there has been slight decline in the extent of both overall food advertisements and advertisements of highfat/high-sugar food products since 2002. Our results have shown that there has been an overall reduction in total food advertisements to $26 \%$ from $31 \%$ over the 4 -year period. The advertising of non-core foods, including highfat/high-sugar foods and its constituent foods, confectionery and fast-food restaurants, has also decreased. The advertising of core food groups, and particularly fruit and vegetables, has increased from 2002 to 2006.

It is important to recognise, however, that the definition of children's viewing time in this comparison was narrower than the band of time which is currently adopted by the commercial television industry. Thus, these findings may indicate either a reduction in advertising to children over this period, or possibly a shift in the concentration of advertising towards viewing times not included in the time band used in 2002, especially to higher-ratings afternoon and evening time slots. It is also possible that these findings may reflect a shift from television advertising towards a wider mix of promotion strategies by food manufacturers. A report by the Institute of Medicine ${ }^{4}$ in the USA outlined that although television advertising still constituted $45 \%$ of food and beverage industries' advertising expenditure, increased emphasis has been placed on other advertising mediums, such as radio, print, billboards and the Internet. Other forms of promotion included sponsorship, inschool marketing, point-of-sale and give-aways. A review by Hasting et l. $^{7}$ states that research into the use of these other marketing tactics is lacking.

This study demonstrates that, under the current Australian regulatory systems, children's exposure to food advertising remains disproportionately high compared with the promotion of more healthful foods. Considering past research about the relationship between advertising exposure and patterns of food consumption ${ }^{4,7}$, it is likely that the levels of advertising of high-fat/highsugar foods, and the targeting of these during high-ratings 
periods, are contributing to excess energy consumption and overweight and obesity among Australian children.

The question for the public health community and Australian society at large is what steps will be required to reduce the level of promotion of unhealthy food products to children? Current Australian regulations do not conform to the criteria proposed by the International Obesity Taskforce $^{23}$, or those under consideration in the UK, where voluntary self-regulation by broadcasters is under scrutiny ${ }^{24}$. Similarly, the US Congress is considering mandatory food advertising regulations for both commercial and cable television ${ }^{7}$. Increasingly it is recognised that voluntary regulations may not be sufficient, and that more transparent, enforceable regulations may be required to reduce the pervasiveness of 'non-core' food advertising ${ }^{7}$.

Experience from the field of tobacco control shows that implementation of stricter regulation of products requires both scientific evidence of health risk and societal acceptance of the introduction of government controls ${ }^{25}$. The body of empirical evidence linking television food advertisements to food choices is growing ${ }^{4,7}$ and is now considered sufficient by a number of bodies, including the Institute of Medicine in the USA and the World Health Organization $^{26,27}$, to warrant stronger regulatory action. This, however, remains contested by the food and advertising industries. The Australian Food and Grocery Council has recently stated that the current regulatory codes are adequate and that any considerations of advertisement bans would be simply a reactive political manoeuvre, and would be inappropriate and ineffectual in defeating rising childhood obesity ${ }^{28}$. Similar arguments, that self-regulation is more effective than government regulation, have been made by the International Advertising Association ${ }^{13}$. Public opinion is the other important ingredient, and in Australia there is evidence of a mandate for action on this issue. A recent survey conducted by $\mathrm{CHOICE}^{29}$ indicated that $82 \%$ of people support greater government regulation of food advertising to children.

Future advertising regulations should consider Australian nutritional recommendations and seek to limit highfat/high-sugar advertisements to approximately 14\% of food advertisements, since this is the maximum proportion of average daily energy intake that the recommended servings of non-core foods would account for in children up to 12 years old ${ }^{11}$. In light of available data on the high prevalence of food advertisements, and particularly advertisements for high-fat/high-sugar foods, information on the effects of advertising on food preferences, purchasing and consumption, and the public support for government regulation, Australia needs to consider further regulatory changes to limit children's exposure.

\section{Acknowledgements}

Sources of funding: The study was funded by NSW Health Department.
Conflict of interest declaration: There were no commercial, personal, political, academic or financial conflicts of interest.

Authorship responsibilities: All authors contributed significantly to the research, including obtaining funding, project design, implementation, management and manuscript writing.

Acknowledgements: We would like to acknowledge the invaluable role of Simon Holding in recording the TV data, and Elizabeth Dunford, Bramilla Patkunanathon and Laxmi Iyengar for their work as research assistants.

\section{References}

1 Chinn S, Rona RJ. Prevalence and trends in overweight and obesity in three cross sectional studies of British children, 1974-94. British Medical Journal 2001; 322: 24-6.

2 Strauss RS, Pollack HA. Epidemic increase in childhood overweight, 1986-1998. Journal of the American Medical Association 2001; 286: 2845-8.

3 Booth ML, Okely T, Denney-Wilson E, Hardy L, Yang B, Dobbins T. NSW Schools Physical Activity and Nutrition Survey (SPANS) 2004: Summary Report. Sydney: NSW Department of Health, 2004.

4 McGinnis MJ, Gootman JA, Kraak VI. Food Marketing to Children and Youth: Threat or Opportunity? Washington, DC: National Academies Press, 2006. Also available at http://books.nap.edu/catalog/11514.html

5 Wiecha JL, Peterson KE, Ludwig DS, Kim J, Sobol A, Gortmaker SL. When children eat what they watch. Impact of television viewing on dietary intake in youth. Archives of Pediatrics \& Adolescent Medicine 2006; 160: 436-42.

6 Halford JCG, Gillespie J, Brown V, Pontin EE, Dovey TM. Effect of television advertisements for foods on food consumption in children. Appetite 2004; 42: 221-5.

7 Hastings G, Stead M, McDermott L, Forsyth A, MacKintosh $\mathrm{AM}$, et al. Review of Research on the Effects of Food Promotion to Children. Prepared for the Food Standard Agency, 22 September 2003.

8 Zywicki TJ, Holt D, Ohlhausen M. Obesity and advertising policy. George Mason Law E Economics Research Paper 2004; 04-45, 979-1011.

9 Lobstein T, Dibb S. Evidence of a possible link between obesogenic food advertising and child overweight. The International Association for the Study of Obesity. Obesity Reviews 2005; 6: 203-8.

10 Australian Government Department of Health and Aging. Australian Guide to Healthy Eating. Canberra: Department of Health and Ageing, 2001. Also available at http://www.health.gov.au/internet/wcms/Publishing.nsf/Content/healthpubhlth-strateg-food-guide-index.htm

11 Bell AC, Kremer PJ, Magarey AM, Swinburn BA. Contribution of 'noncore' foods and beverages to the energy intake and weight status of Australian children. European Journal of Clinical Nutrition 2005; 59: 639-45.

12 Wilson N, Signal L, Nicholls S, Thomson G. Marketing fat and sugar to children on New Zealand television. Preventive Medicine 2006; 42: 96-101.

13 Caraher M, Landon J, Dalmeny K. Television advertising and children: lessons from policy development. Public Health Nutrition 2005; 9: 596-605.

14 Kunkel D, Wilcox BL, Cantor J, Palmer E, Linn S, Dowrick P. Psychological issues in the increasing commercialization of childhood. In: Report of the APA Task Force on Advertising and Children. Washington, DC: American Psychological Association, 20 February 2004. 
15 International Chamber of Commerce. International Code of Advertising Practice [online], 1997. Available at http:// www.itcilo.it/english/actrav/telearn/global/ilo/guide/iccadv.htm. Accessed 6 February 2007.

16 Australian Communications and Media Authority. Children's Television Standards [online], 1 July 2005. Available at http://www.amca.gov.au/acmainterwr/aba/contnetreg/codes/television/documents/children_t_v_standards_2005 pdf. Accessed 6 February 2007.

17 Australian Bureau of Statistics (ABS). Regional Population Growth, Australia, 2004-05 [online], February 2006. Available at http://www.abs.gov.au/ausstats/abs@. nsf/Latestproducts/3218.0Media\%20Release2004-05?open document\&tabname $=$ Summary $\&$ prodno $=3218.0 \&$ \&ssue $=2004$ $-05 \&$ num $=\& v i e w=$. Accessed 6 February 2007.

18 Neville L, Thomas M, Bauman A. Food advertising on Australian television: the extent of children's exposure. Health Promotion International 2005; 20: 105-12.

19 OzTAM, Australian Television Audience Measurement, homepage http://www.oztam.com.au/html/

20 Rodd HD, Patel V. Content analysis of children's television advertising in relation to dental health. British Dental Journal 2005; 199: 710-3.

21 Kotz K, Story M. Food advertisements during children's Saturday morning television programming: are they consistent with dietary recommendations? Journal of the American Dietetic Association 1994; 94: 1296-300.

22 Chapman K, Nicholas P, Supramaniam R. How much food advertising is there on Australian television? Health Promotion International 2006; 21: 172-80.
23 Lobstein T, Baur L. Uauy R for the International Obesity Taskforce Childhood Obesity Working Group. Obesity in children and young people: a crisis in public health. Obesity Reviews 2004; 6(Suppl. 1): 4-85.

24 Ofcom. Department of Office of Communications. Television Advertising of Food and Drink Products to Children, Consultation annexes [online], March 2006. Available at http://www.ofcom.org.uk/consult/condocs/foodads/food adsprint/. Accessed 6 February 2007.

25 Mello MM, Studdert DM, Brennan TA. Health policy report. Obesity - the new frontier of public health law. New England Journal of Medicine 2006; 354: 2601-10.

26 World Health Organization (WHO). Diet, Nutrition and the Prevention of Chronic Diseases. Report of a Joint WHO/FAO consultation. Technical Report Series No. 916. Geneva: WHO, 2003.

27 World Health Organization. World Health Assembly Resolution WHA57.17 - Global Strategy on Diet, Physical Activity and Health [online], 2004. Available at http://www. who.int/dietphysicalactivity/goals/en/. Accessed 6 February 2007.

28 Australian Food and Grocery Council. Media Release Tackling Obesity - Food and Beverage Industry Playing its Part [online], 27 July 2006. Available at http://www. afgc.org.au/cmsDocuments/Media\%20Release\%20HeathMInConf July06.pdf. Accessed 6 February 2007.

29 CHOICE. Childhood Obesity. Our Survey: Results Table. 2006 [online]. Available at http://www.choice.com.au/ viewArticle . aspx? $\mathrm{id}=105438 \&$ catId $=100512 \& \mathrm{tid}=100008 \&$ $\mathrm{P}=2 \&$ title $=$ Childhood + obesity. Accessed 6 February 2007. 